\title{
Late Diagnosis of Congenital Methemoglobinemia in a 33-year-old Patient, Case Report and Review of Literature
}

\author{
Maya Aldeeb ${ }^{1}$ and mohamed yassin ${ }^{2}$ \\ ${ }^{1}$ Hamad Medical Corporation \\ ${ }^{2} \mathrm{HMC}$ NCCCR
}

November 19, 2020

\begin{abstract}
This is a case of recurrent episodes of headache and cyanosis who has never been diagnosed despite frequent visits to the hospital. After excluding cardiopulmonary causes, methemoglobin levels were found to be high, without exposure to any offending agent. Also, we did a literature review about congenital methemoglobinemia.
\end{abstract}

Late Diagnosis of Congenital Methemoglobinemia in a 33-year-old Patient, Case Report and Review of Literature:

Maya Aldeeb ${ }^{1^{*}}$ and Mohamed A. Yassin ${ }^{2}$

1 Department of medical education, Family Medicine Residency Program, Hamad Medical Corporation, Doha, Qatar; ${ }^{2}$ Department of Hematology and Medical Oncology, National Center for Cancer Care and Research, Hamad Medical Corporation, Doha, Qatar

${ }^{*}$ Corresponding Author

Correspondence: Maya Aldeeb, Family Medicine Department, Hamad Medical Corporation, Al Rayan Street,Doha, PO Box 3050, Qatar. Email: Maldeeb@hamad.qa

Funding information :Qatar Foundation

Keywords:

Methemoglobinemia, Congenital, Cyanosis, Asian.

Key clinical message:

Congenital methemoglobinemia is rarely diagnosed and reported as a cause of cyanosis, especially in adults. It is a treatable cause of cyanosis that should be kept in our differential diagnosis.

Abstract:

Cyanosis and dyspnea are common complaints in adults and have broad differential diagnoses, of which rare ones as congenital methemoglobinemia should always be kept in mind. Methemoglobinemia might be acquired or congenital. Patients' symptoms vary from severe shortness of breath, mental status changes, cyanosis to none.

Here we present a rare case of a 33-year-old Indian non-smoker female, who had a long history of recurrent episodes of cyanosis, headache, and fatigue. After excluding cardiopulmonary causes, methemoglobin levels were measured and found to be high, without exposure to any offending agent. Consequently, we suspected a diagnosis of congenital methemoglobinemia and started treatment with ascorbic acid, and she improved. 
In this article, we summarized our patient's presentation and did a literature review about congenital methemoglobinemia.

\section{Introduction:}

Methemoglobinemia, a form of hemoglobinopathies, is defined as an increased methemoglobin level, where the ferric form of iron is attached to heme instead of ferrous. This will reduce tissue oxygenation ${ }^{1}$. A percentage of hemoglobin will be oxidized to methemoglobin under any oxidative stress, but this is regulated by special enzymes to keep it in normal individuals less than $1.5 \%$. Usually, cyanosis appears when methemoglobin levels exceed $1.5 \mathrm{~g} / \mathrm{dl}$, around $15 \%$ of total hemoglobin; most adults with methemoglobinemia have the acquired type due to exposure to an offending agent. Whereas having unexplained methemoglobinemia in an adult should raise the possibility of the congenital type, which is extremely rare.

Three genetic causes lie behind congenital methemoglobinemia ${ }^{2}$ :

1.CYB5R3 gene pathogenic variations lead to autosomal recessive cytochrome b5 reductase deficiency. This genetic phenotype causes two types of methemoglobinemia; type 1, RBC type, might be asymptomatic and type 2 , other cells, were patients will have neurologic manifestations.

2. Point mutation in alpha-globin gene causing hemoglobin $\mathrm{M}$, an autosomal dominant disease.

3. Cytochrome b5 deficiency, extremely rare.

Our patient presented with shortness of breath of 3 days duration with bluish discoloration of her fingers and lips. Her complaint was not associated with chest pain, cough, wheezes, or any other symptoms. she had recurrent similar episodes since childhood but milder. A mismatch between oxygen saturation by pulse oximetry and blood gases raised the possibility of methemoglobinemia. We suspected the congenital methemoglobinemia type 1 and initiated treatment with a high dose of ascorbic acid; after ruling out the causes of acquired methemoglobinemia, and the patient improved clinically.

\section{Case presentation:}

This is a case 33-year-old Indian lady seen in the emergency room for difficulty breathing with bluish discoloration gradually increased over days, with no fever or cough. She mentioned having recurrent similar episodes since childhood, exacerbated by infections, but usually milder. No previous surgical or medical history, except for one admission last year for shortness of breath with cyanosis, required oxygen support for one day and then discharged home with no diagnosis, and chronic headache.

One sister has similar cyanosis symptoms, who had surgery complicated with low saturation and severe cyanosis during anesthesia. Both have never been investigated. Her other three siblings and parents do not have any symptoms.

Physical examination was normal except for central and peripheral cyanosis; the chest was clear, with no wheezes, no crackles. Cardiac examination, no murmurs or abnormal heart sounds. Abdominal examination, no organomegaly appreciated.

Height: $167 \mathrm{~cm}$, weight: $66 \mathrm{~kg}$, BMI: $23.7 \mathrm{~kg} / \mathrm{m} 2$, SpO2: $90 \%$ sometimes dropping to $88 \%$ on room air, HR: 77 beat/minute, BP: 105/80 mmHg, RR: 20 breath/min

Investigations:

Patient had normal liver function tests results, G6PD scan: normal other laboratory results and ABG result in table (1).

Peripheral blood smear demonstrated mild erythrocytosis with no other abnormalities. Electrocardiography showed normal sinus rhythm. Chest radiography showed clear lung fields and a heart of normal size and contour. There were no abnormalities of the hilar, mediastinal, pleural, or bony structures. 
The patient's clinical picture of cyanosis with no evidence of cardiovascular or pulmonary diseases and the discrepancy between $\mathrm{PaO} 2$ and $\mathrm{O} 2$ saturation on oximeter required thinking of methemoglobinemia as a possible diagnosis despite the patient's age and the absence of any exposures. Methemoglobin level $20.9 \%$ (0-1.5\%). Hemoglobin electrophoresis did not detect any abnormal hemoglobin.

The activity of NADH cytochrome $b_{5}$ reductase or the level were not done.

Discussion:

Methemoglobinemia is a result of defective regulation of the methemoglobin level by the responsible pathways after oxidative stress. In normal individuals, methemoglobin results from oxidation of ferrous iron that binds to heme to ferric iron, which decreases its ability to bind to oxygen, leading to less oxygen delivery to tissues and left shift in oxygen dissociation curve ${ }^{11} / 17 / 2020$ 5:33:00 PM. Affected individuals can have cyanosis, but clinically significant tissue hypoxia is unusual as compensatory erythrocytosis improves oxygen delivery.

Methemoglobinemia might be acquired or congenital. For acquired methemoglobinemia, a myriad of causes has been described in the literature of which: medication as dapsone, lidocaine, nitrates, sulfa drugs ${ }^{3,4,5}$. The clinical consequences depend upon methemoglobin levels in the blood; symptoms will start at a level $>10 \%$, then nausea, tachycardia occurs with level $<30 \%$, while $50 \%$ level leads to neurological deterioration. Higher levels can cause arrhythmia, while more than $70 \%$ of methemoglobin is considered fatal ${ }^{2,3}$. The acquired form's symptoms are affected by the speed of the increase in the levels and the half-life of the causative agent. Mostly those patients require treatment with intravenous methylene blue.

Conversely, congenital methemoglobinemia causes milder presentation as it is a chronic elevation in methemoglobin with a physiologic compensatory erythrocytosis. NADH cytochrome b5 reductase deficiency congenital methemoglobinemia is further classified into two subcategories. Type 1, enzyme deficiency in the erythrocytes, those patients are usually asymptomatic or will present late with cyanosis, fatigue, some shortness of breath-treatment for cosmetic reasons mostly ${ }^{10,23}$. Type 2 , generalize deficiency of cytochrome b5 in all body tissues, is accompanied by neurological disabilities; however, it is not amenable to treatment at this time.

While acquired methemoglobinemia, triggered by oxidative means, is common, congenital causes are uncommon and rarely documented in the literature ${ }^{10}$.

Here we tried to summarize the English published literature about congenital methemoglobinemia in table (2)

\section{Conclusion:}

Due to mild symptoms, congenital methemoglobinemia is rarely diagnosed and reported as a cause of the cyanosis, especially in adults. Despite the benign nature of congenital methemoglobinemia, it is crucial to keep it in the differential diagnosis list when assessing cyanotic patients, mainly if he has a normal $\mathrm{PaO} 2$. Patients are usually asymptomatic and are treated for cosmetic purposes, but they might suffer from severe complications if exposed to oxidative agents.

In summary, congenital methemoglobinemia is a rare but treatable cause of cyanosis that should be considered in the differential diagnosis of cyanosis.

\section{Acknowledgment:}

We thank Hamad Medical Corporation, especially hematology section NCCCR and family medicine residency program. Open Access funding provided by the Qatar National Library.

Conflict of interest:

None to identify.

Statement of ethics:Consent was obtained from the patients. Case was approved by HMC Medical Research Center. 
Data availability statement: All data related to this article are available upon request.

Author contribution: MA, MY: were involved in data collection, analysis, and interpretation. MAwrote the manuscript. MYcritically revised the manuscript.

ORCID: Maya Aldeeb https://orcid.org/0000-0002-2748-6990 Mohamed A. Yassin https://orcid. org/00000002-1144-8076

\section{References:}

1. Wright, R. O., Lewander, W. J., \& Woolf, A. D. (1999). Methemoglobinemia: etiology, pharmacology, and clinical management. Annals of emergency medicine, 34 (5), 646-656.

2. Gibson, Q. H. (1948). The reduction of methaemoglobin in red blood cells and studies on the cause of idiopathic methaemoglobinaemia. Biochemical Journal , 42 (1), 13-23.

3. Ríos, J. D. P., Yong, R., \& Calner, P. (2019). Code Blue: life-threatening methemoglobinemia. Clinical Practice and Cases in Emergency Medicine, 3 (2), 95.

4. Cortazzo, J. A., \& Lichtman, A. D. (2014). Methemoglobinemia: a review and recommendations for management. Journal of cardiothoracic and vascular anesthesia , 28 (4), 1043-1047.

5. Kuschner, W. G., Chitkara, R. K., Canfield Jr, J., Poblete-Coleman, L. M., Cunningham, B. A., \& Sarinas, P. S. (2000). Benzocaine-associated methemoglobinemia following bronchoscopy in a healthy research participant. Respiratory care , 45 (8), 953-956.

6. Viršilas, E., Timukienè, L., \& Liubšys, A. (2019). Congenital methemoglobinemia: Rare presentation of cyanosis in newborns. Clinics and practice, 9 (4).

7. Ara, T., Haque, Q. S., \& Afrose, S. (2019). A Rare Case of Congenital Methemoglobinemia with secondary polycythemia-Case Report and Literature Review. Haematology Journal of Bangladesh , 3 (01), 20-23.

8. Firouzabadi, L. I., \& Mead, P. (2020). Congenital methaemoglobinaemia presenting in a 55-year-old man. BMJ Case Reports , 13 (9).

9. Ji, J., Liu, Y., \& Chen, M. (2020). Type I congenital methemoglobinemia in a Chinese family. Annals of Hematology, 1-3.

10. Soliman, D. S., \& Yassin, M. (2018). Congenital methemoglobinemia misdiagnosed as polycythemia vera: Case report and review of literature. Hematology reports , 10 (1).

11. Kitao, T., Sugita, Y., Yoneyama, Y., \& Hattori, K. (1974). Methemoglobin reductase (cytochrome b5 reductase) deficiency in congenital methemoglobinemia. Blood , 44 (6), 879-884.

12. Da-Silva, S. S., Sajan, I. S., \& Underwood, J. P. (2003). Congenital methemoglobinemia: a rare cause of cyanosis in the newborn-a case report. Pediatrics , 112 (2), e158-e161.

13. Aslan, D., Türköz-Sucak, G., \& Percy, M. J. (2016). Recessive congenital methemoglobinemia in immediate generations. The Turkish journal of pediatrics , 58 (1), 113.

14. Rao, B. N., Sinha, S. C., Modi, S., \& Sunita, S. (2017). Healthy blue man: congenital methemoglobinemia. International Journal of Research in Medical Sciences , 5 (10), 4632.

15. Londhey, V., Khadilkar, K., Gad, J., Chawla, B., \& Asgaonkar, D. (2014). Congenital methemoglobinemia: a rare cause of cyanosis in an adult patient. The Journal of the Association of Physicians of India , 62 (3), 269-271.

16. Tasci, C., Nevruz, O., Candir, N., \& Bilgic, H. (2012). A methemoglobinemia case who was previously diagnosed and treated as asthma. Respiratory medicine case reports , 6 , 11-12. 
17. Hamirani, Y. S., Franklin, W., Grifka, R. G., \& Stainback, R. F. (2008). Methemoglobinemia in a young man. Texas Heart Institute Journal , 35 (1), 76.

18. Badawi, M. A., Badawi, M. A., Wali, S. O., \& Alsaggaf, R. Z. (2016). Hereditary methemoglobinemia manifesting in adolescence. Journal of Applied Hematology, 7 (3), 108.

19. Ramanamurthy, S. V. (2013). Methemoglobinemia: a reappraisal with an Indian perspective. Hematology

20. Trivedi, D. J., Joshiraj, B., Bidkar, V., \& Rao, R. (2017). Methemoglobinemia: living with dormant devil. Indian Journal of Clinical Biochemistry , 32 (2), 248-250.

21. Gerli, G. C., Beretta, L., Bianchi, M., Bernasconi, C., Morandi, M., Adami, R., \& Ferrari, A. (1981). Methemoglobinemia; a description of a case of NADH methemoglobulin reductase deficiency. Minerva medica , 72 (29), 1925-1930.

22. Kedar, P., Warang, P., Ghosh, K., \& Colah, R. (2012). Recessive congenital methemoglobinemia due to NADH-cytochrome b5 reductase deficiency associated with recurrent early pregnancy loss (REPL) in an Indian family. Annals of hematology , 91 (12), 1985.

23. Percy, M. J., Gillespie, M. J., Savage, G., Hughes, A. E., McMullin, M. F., \& Lappin, T. R. (2002). Familial idiopathic methemoglobinemia revisited: original cases reveal 2 novel mutations in NADH-cytochrome b5 reductase. Blood , 100 (10), 3447-3449.

24. Vives-Corrons, J. L., Pujades, A., Vela, E., Corretger, J. M., Leroux, A., \& Kaplan, J. C. (1978). Congenital methemoglobin-reductase (cytochrome b5 reductase) deficiency associated with mental retardation in a Spanish girl. Acta haematologica , 59 (6), 348-353.

25. Yawata, Y., Ding, L., Tanishima, K., \& Tomoda, A. (1992). New variant of cytochrome b5 reductase deficiency (b5RKurashiki) in red cells, platelets, lymphocytes, and cultured fibroblasts with congenital methemoglobinemia, mental and neurological retardation, and skeletal anomalies. American journal of hematology , 40 (4), 299-305.

26. Kedar, P. S., Nadkarni, A. H., Phanasgoankar, S., Madkaikar, M., Ghosh, K., Gorakshakar, A. C., .. \& Mohanty, D. (2005). Congenital methemoglobinemia caused by Hb-MRatnagiri ( $\beta-63 C A T-$ TAT, His- Tyr) in an Indian family. American journal of hematology , 79 (2), 168-170.

27. Nellicka S, John A, Abraham V. CONGENITAL METHEMOGLOBINEMIA TYPE 2 - A RARE CASE REPORT. Pediatr Oncall J. 2017;14: 45-46. doi: 10.7199/ped.oncall.2017.19

Table legends:

Table (1) laboratory results

Table (2) literature review summary

\section{Hosted file}

table 1.pdf available at https://authorea.com/users/377042/articles/493854-late-diagnosisof-congenital-methemoglobinemia-in-a-33-year-old-patient-case-report-and-review-ofliterature

\section{Hosted file}

table 2.1.pdf available at https://authorea.com/users/377042/articles/493854-late-diagnosisof-congenital-methemoglobinemia-in-a-33-year-old-patient-case-report-and-review-ofliterature 